\title{
ADVANCED HYBRID PARTICULATE COLLECTOR - PHASE III
}

\section{Quarterly Technical Progress Report}

for the period January 1 through March 31, 2001

Prepared for:

AAD Document Control

U.S. Department of Energy

National Energy Technology Laboratory

PO Box 10940, MS 921-143

Pittsburgh, PA 15236-0940

DOE Contract No. DE-FC26-99FT40719; UND Fund 4593

Performance Monitor: William Aljoe

Prepared by:

Stanley J. Miller

Ye Zhuang

Michelle R. Olderbak

Energy \& Environmental Research Center University of North Dakota

PO Box 9018

Grand Forks, ND 58202-9018 


\section{EERC DISCLAIMER}

LEGAL NOTICE This research report was prepared by the Energy \& Environmental Research Center (EERC), an agency of the University of North Dakota, as an account of work sponsored by National Energy Technology Laboratory. Because of the research nature of the work performed, neither the EERC nor any of its employees makes any warranty, express or implied, or assumes any legal liability or responsibility for the accuracy, completeness, or usefulness of any information, apparatus, product, or process disclosed, or represents that its use would not infringe privately owned rights. Reference herein to any specific commercial product, process, or service by trade name, trademark, manufacturer, or otherwise does not necessarily constitute or imply its endorsement or recommendation by the EERC.

\section{DISCLAIMER}

This report was prepared as an account of work sponsored by an agency of the United States Government. Neither the United States Government, nor any agency thereof, nor any of their employees makes any warranty, express or implied, or assumes any legal liability or responsibility for the accuracy, completeness, or usefulness of any information, apparatus, product, or process disclosed or represents that its use would not infringe privately owned rights. Reference herein to any specific commercial product, process, or service by trade name, trademark, manufacturer, or otherwise does not necessarily constitute or imply its endorsement, recommendation, or favoring by the United States Government or any agency thereof. The views and opinions of authors expressed herein do not necessarily state or reflect those of the United States Government or any agency thereof.

This report is available to the public from the National Technical Information Service, U.S. Department of Commerce, 5285 Port Royal Road, Springfield, VA 22161; phone orders accepted at (703) $487-4650$.

\section{ACKNOWLEDGMENT}

This report was prepared with the support of the U.S. Department of Energy (DOE) National Energy Technology Laboratory Contract No. DE-FC26-99FT40719. However, any opinions, findings, conclusions, or recommendations expressed herein are those of the authors(s) and do not necessarily reflect the views of DOE. 


\section{TABLE OF CONTENTS}

LIST OF FIGURES $\ldots \ldots \ldots \ldots \ldots \ldots \ldots \ldots \ldots \ldots \ldots \ldots \ldots \ldots \ldots \ldots \ldots$ ii

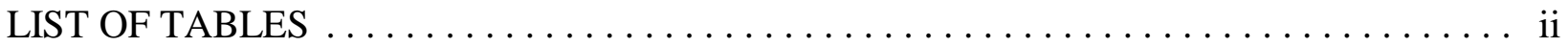

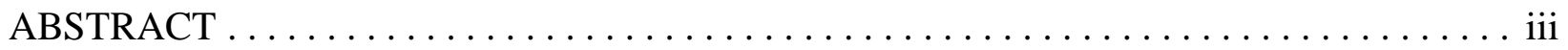

EXECUTIVE SUMMARY $\ldots \ldots \ldots \ldots \ldots \ldots \ldots \ldots \ldots \ldots \ldots \ldots \ldots \ldots \ldots \ldots$

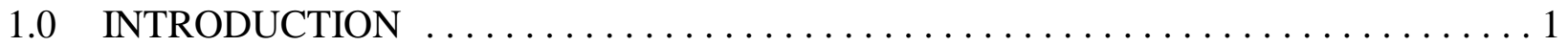

2.0 PHASE III OBJECTIVES AND PLANNED WORK $\ldots \ldots \ldots \ldots \ldots \ldots \ldots \ldots \ldots \ldots$.

3.0 AHPC BENCH-SCALE EXPERIMENTS AND TESTING RESULTS . . . . . . . . 2

4.0 TWO DIMENSIONAL (2-D) MODEL OF ELECTRICAL FIELD FOR THE PILOTSCALE AHPC IN THE PRESENCE OF PERFORATED PLATE $\ldots \ldots \ldots \ldots \ldots \ldots \ldots 5$

$5.09000-\operatorname{acfm}\left(255-\mathrm{m}^{3} / \mathrm{min}\right)$ AHPC DESIGN CHANGES AND TEST RESULTS $\ldots \ldots \ldots 7$

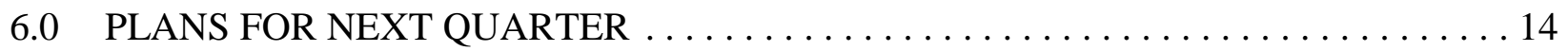




\section{LIST OF FIGURES}

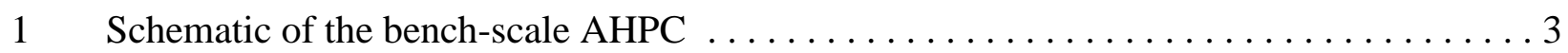

2 Current to the bags as a function of spacing between electrode and the bag $\ldots \ldots \ldots \ldots 4$

3 Current to the bags as a function of spacing between the electrode and the bag $\ldots \ldots \ldots 4$

4 Current to the bag in the presence of different perforated plates $\ldots \ldots \ldots \ldots \ldots \ldots 5$

5 Current to the bag in the presence of different perforated plates $\ldots \ldots \ldots \ldots \ldots \ldots$

6 Current to the bag in the presence of different perforated plates $\ldots \ldots \ldots \ldots \ldots \ldots 6$

7 Electrical potential distributed in the pilot unit AHPC with the 1.0-in. hole size

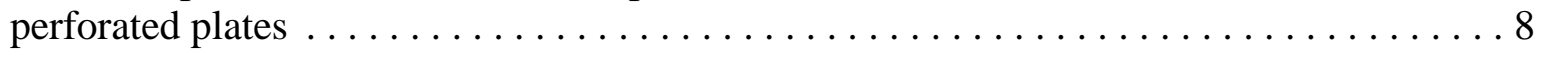

8 Electrical potential distributed in the pilot unit AHPC with the 2.0-in. hole size

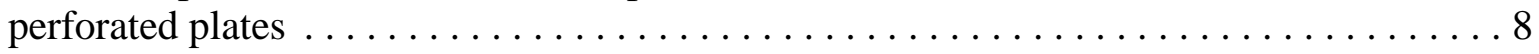

9 Electrical potential distributed in the pilot unit AHPC with the 2.5-in. hole size

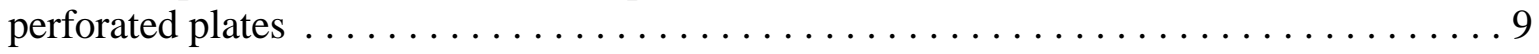

10 Electric potential distribution in the AHPC pilot unit without the perforated plates . . . . 9 9

11 Top view of the $9000-\operatorname{acfm}\left(255-\mathrm{m}^{3} / \mathrm{min}\right)$ AHPC, as modified at the start of Phase III . 10

12 Top view of the perforated plate configuration for the $9000-\mathrm{acfm}\left(255-\mathrm{m}^{3} / \mathrm{min}\right)$ AHPC .10

13 Installing the perforated plates in the $9000-\operatorname{acfm}\left(255-\mathrm{m}^{3} / \mathrm{min}\right)$ AHPC at the Big Stone

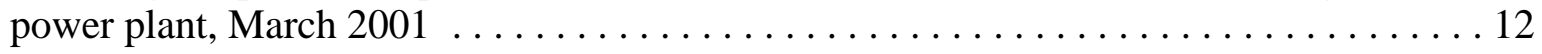

14 Perforated plates as installed in the $9000-\mathrm{acfm}\left(255-\mathrm{m}^{3} / \mathrm{min}\right)$ AHPC before replacing the

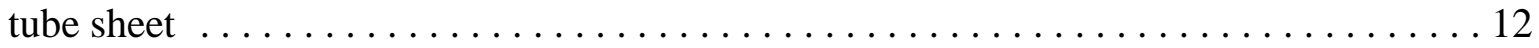

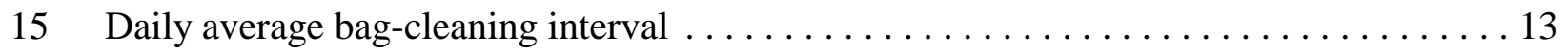

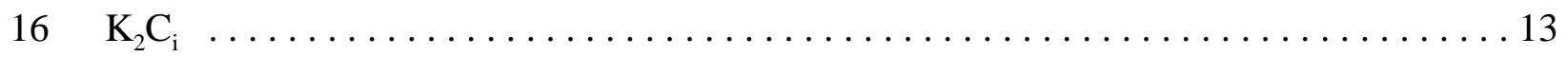

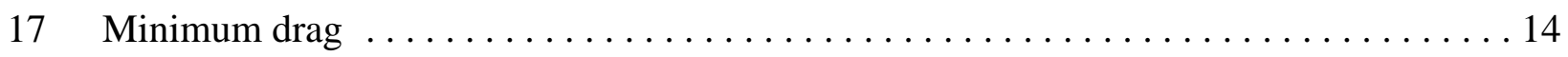

\section{LIST OF TABLES}

1 Parameters Evaluated in the Bench-Scale Experiments . ................... 2 


\title{
ADVANCED HYBRID PARTICULATE COLLECTOR - PHASE III
}

\begin{abstract}
A new concept in particulate control, called an advanced hybrid particulate collector (AHPC), is being developed under funding from the U.S. Department of Energy. The AHPC combines the best features of electrostatic precipitators (ESPs) and baghouses in a unique configuration. The AHPC concept consists of a combination of fabric filtration and electrostatic precipitation in the same housing, providing major synergism between the two collection methods, both in the particulate collection step and in the transfer of dust to the hopper. The AHPC provides ultrahigh collection efficiency, overcoming the problem of excessive fineparticle emission with conventional ESPs, and it solves the problem of reentrainment and re-collection of dust in conventional baghouses. In Phase II, a 2.5-MW-scale AHPC was designed, constructed, installed, and tested at the Big Stone power plant. For Phase III, further testing of an improved version of the 2.5-MW-scale AHPC at the Big Stone power plant is being conducted to facilitate commercialization of the AHPC technology.
\end{abstract}




\section{ADVANCED HYBRID PARTICULATE COLLECTOR - PHASE III}

\section{EXECUTIVE SUMMARY}

A new concept in particulate control, called an advanced hybrid particulate collector (AHPC), is being developed at the Energy \& Environmental Research Center (EERC) with U.S. Department of Energy (DOE) funding. In addition to DOE and the EERC, the project team includes W.L. Gore \& Associates, Inc., Allied Environmental Technologies, Inc., and the Big Stone power plant. The AHPC combines the best features of electrostatic precipitators (ESPs) and baghouses in a unique approach to develop a compact but highly efficient system. Filtration and electrostatics are employed in the same housing, providing major synergism between the two collection methods, both in the particulate collection step and in the transfer of dust to the hopper. The AHPC provides ultrahigh collection efficiency, overcoming the problem of excessive fine-particle emissions with conventional ESPs, and solves the problem of reentrainment and re-collection of dust in conventional baghouses.

The objective of the project is to develop a highly reliable AHPC that can provide $>99.99 \%$ particulate collection efficiency for particle sizes from 0.01 to $50 \mu \mathrm{m}$, is applicable for use with all U.S. coals, and is less costly than existing technologies.

Phase I of the development effort consisted of design, construction, and testing of a 200-acfm (5.7- $\left.\mathrm{m}^{3} / \mathrm{min}\right)$ working AHPC model. Results from both 8- and 100-hr tests showed that the concept worked well, achieving greater than $99.99 \%$ collection efficiency for fine particles at high filtration velocities.

Since all the developmental goals of Phase I were met, the approach was scaled up in Phase II to a size of $9000 \mathrm{acfm}\left(255 \mathrm{~m}^{3} / \mathrm{min}\right)$ and was installed on a slipstream at the Big Stone power plant.

For Phase II, the AHPC at Big Stone power plant was operated continuously from late July 1999 until mid-December 1999, except for a 3-week down period in September corresponding to an annual plant outage. The Phase II results were highly successful in that ultrahigh particle collection efficiency was achieved, pressure drop was well controlled, and system operability was excellent.

The developmental objective for Phase III is to obtain the necessary engineering data to facilitate scale up of the AHPC to the full-scale demonstration size for near-term commercialization of this technology. The test plan includes seven 1-month tests at the 9000-acfm (255- $\left.\mathrm{m}^{3} / \mathrm{min}\right)$ field AHPC unit at Big Stone power plant: six to address a specific primary variable and one to serve as a contingency test. The AHPC field unit was successfully operated from April to July 2000. The results, as discussed in the previous quarterly reports, showed that the AHPC exceeded the performance goals of a 10-min bag-cleaning interval at an air-to-cloth ratio of $12 \mathrm{ft} / \mathrm{min}(3.7 \mathrm{~m} / \mathrm{min})$ and 8 -in. W.C. $(2.0 \mathrm{kPa})$ pressure drop. Additional 
testing with the $200-\mathrm{acfm}\left(5.7-\mathrm{m}^{3} / \mathrm{min}\right)$ AHPC at the EERC was also completed from August through October to evaluate design and geometric spacing.

Some membrane damage that appeared to be electrical in nature was observed on the bags. Extensive studies were carried out to determine the reason for the observed bag damage and to find possible solutions without compromising AHPC performance. The best solution to prevent the bag damage was found to be perforated plates installed between the electrodes and the bags, which can block the electric field from the bag surface and intercept current to bags. The experimental data from tests at the EERC conducted in October 2000 showed that the results were far better than any other tests. The perforated plate not only solved the bag damage problem, but also appeared to offer many other advantages such as operation at higher $\mathrm{A} / \mathrm{C}$ ratios, lower pressure drop, and an even more compact geometric arrangement.

In order to better understand the effect of the perforated plates on bag protection as well as AHPC overall performance and to optimize the perforated plate design, a bench-scale experimental system was designed and built to measure the current to the bags under several perforated plate configurations. Also, a theoretical model was developed to simulate the electric field in the AHPC pilot unit with the presence of perforated plate to examine its effects on bag protection. All the results indicate that the presence of a perforated plate between the electrodes and the bags can effectively reduce the electric field strength around the bags. Based on these results and experimental data from additional AHPC pilot studies (completed under a separate DOE-funded project), design modifications were made and implemented to the 9000 -acfm $\left(255-\mathrm{m}^{3} / \mathrm{min}\right)$ AHPC field unit at the Big Stone power plant.

The modified Big Stone AHPC was started on March 15, 2001, and has been in continuous operation to date. The AHPC functions extremely well at a long bag-cleaning interval (26-68 minutes), a low $\mathrm{K}_{2} \mathrm{C}_{\mathrm{i}}(1.8-3)$, and a low residual drag (0.50-0.55). 


\section{ADVANCED HYBRID PARTICULATE COLLECTOR - PHASE III}

\subsection{INTRODUCTION}

This project was awarded under the U.S. Department of Energy (DOE) Program Solicitation DE-PA26-99FT40251 and specifically addresses Technical Topical Area 3 - Primary PM Emissions Control. Phase III is a logical continuation of the development toward full-scale commercialization of the advanced hybrid particulate collector (AHPC).

In 1994, The University of North Dakota (UND) Energy \& Environmental Research Center (EERC) responded to DOE Program Research and Development Announcement (PRDA) No. DE-RA22-94PC92291, Advanced Environmental Control Technologies for Coal-Based Power Systems Phases I and II, under Topic 7: Advanced Concepts for Control of Fine Particles and Vapor-Phase Toxic Emissions. The EERC proposal was subsequently selected for DOE funding, and the EERC was awarded Contract DE-AC22-95PC95258. Phase I work consisted of initial development of the AHPC starting as a completely new concept without any supporting experimental data. Following highly successful results from the Phase I work, the EERC submitted a Phase II downselection proposal to DOE in June 1997 to continue development of the AHPC. The 2-year Phase II contract was awarded in March 1998 and included additional 200 -acfm $\left(5.7-\mathrm{m}^{3} / \mathrm{min}\right)$ testing, similar to the tests completed in Phase I, as well as the design, construction, installation at a full-scale power plant, and testing of a $9000-\mathrm{acfm}\left(255-\mathrm{m}^{3} / \mathrm{min}\right.$ [2.5-MW equivalent]) version of the AHPC. The Phase II testing was completed in December 1999. Following completion of several modifications and improvements to the Phase II AHPC, Phase III testing began in mid-April 2000.

\subsection{PHASE III OBJECTIVES AND PLANNED WORK}

The objective of the project is to develop a highly reliable AHPC that can provide $>99.99 \%$ particulate collection efficiency for all particle sizes from 0.01 to $50 \mu \mathrm{m}$, is applicable for use with all U.S. coals, and is less costly than existing technologies. This goal has remained unchanged since the concept was originally proposed in 1994. The approach objective with the AHPC is to utilize filtration and electrostatic mechanisms in a unique manner that is superior to conventional fabric filters and electrostatic precipitators (ESPs).

The field AHPC unit was successfully started up in April 2000 and was operated for a period of about 3 months through July 2000. Additional testing with the $200-\mathrm{acfm}\left(5.7-\mathrm{m}^{3} / \mathrm{min}\right)$ AHPC at the EERC was also completed from August through October to evaluate electrode design and geometric spacing. Details of these results were discussed in the April-June and July-September 2000 Quarterly Technical Progress Reports. As mentioned in the reports, some bag damage was noted in the tests at Big Stone power plant that appeared to be electrical in nature. 
To evaluate the cause of the bag damage observed, experiments were completed at the EERC to investigate the interactions between electrostatics and bags under different operating conditions. One option to solve the electrically induced bag damage observed in the previous study is to put ground wires between the electrodes and the bags, which can block the electrical field from the bag surface and intercept current to bags. A variation of this idea is using perforated plates instead of the grounded wires in the AHPC system. The experimental data from tests at the EERC conducted in October 2000 show that the results were far better than any other tests. The perforated plate not only appears to be the best solution to solve the bag damage problem, but also appears to offer many other advantages such as operation at higher $\mathrm{A} / \mathrm{C}$ ratios, lower pressure drop, and an even more compact geometric arrangement. In summary, we believe that this new configuration is a major improvement.

During this period, bench-scale experiments and theoretical studies were performed to obtain more detailed information on bag protection by using the perforated plate configuration. Based on the above results and experimental data from AHPC pilot studies (completed for a separate project), design modifications were made to the $9000-\mathrm{acfm}\left(255 \mathrm{~m}^{3} / \mathrm{min}\right)$ AHPC unit at Big Stone power plant. The Big Stone AHPC was started on March 15, 2001.

\subsection{AHPC BENCH-SCALE EXPERIMENTS AND TESTING RESULTS}

As discussed in the October-December 2000 quarterly report, the perforated plate configuration effectively reduced the current to the bags which was believed to correlate with the observed bag damage. To better understand the interactions between the electrical field and bag fabric in the presence of a perforated plate, a bench-scale experimental system was designed and built to measure the current to the bags under several perforated plate configurations. The schematic diagram of the system is shown in Figure 1. The high voltage from the DC power unit is applied to the electrode to generate corona. The ionic current, flowing downstream (as shown in Figure 1) toward the bag surface, is intercepted by the installed perforated plate because of the diversion of electrical field to the plate. The spacings between the electrode, the perforated plate, and the bag surface are adjustable. The bag fabric is isolated from the chamber to measure the current to bag by using an ammeter. The evaluated parameters are listed in Table 1.

\section{TABLE 1}

Parameters Evaluated in the Bench-Scale Experiments

\begin{tabular}{ll}
\hline Spacing of Bag to Perforated Plate (BTP, in. [mm]) & $1.5-2.5(38.1-63.5)$ \\
Spacing of Perforated Plate to Electrode (PTE, in. [mm]) & $2.5-4.5(63.5-114.3)$ \\
Spacing of Bag to Electrode (BTE, in. [mm]) & $4-6(101.6-152.4)$ \\
Perforated Plate Hole Size (in. [mm]) & $0.75,1.00,1.50(19.1,25.4,38.1)$ \\
\hline
\end{tabular}




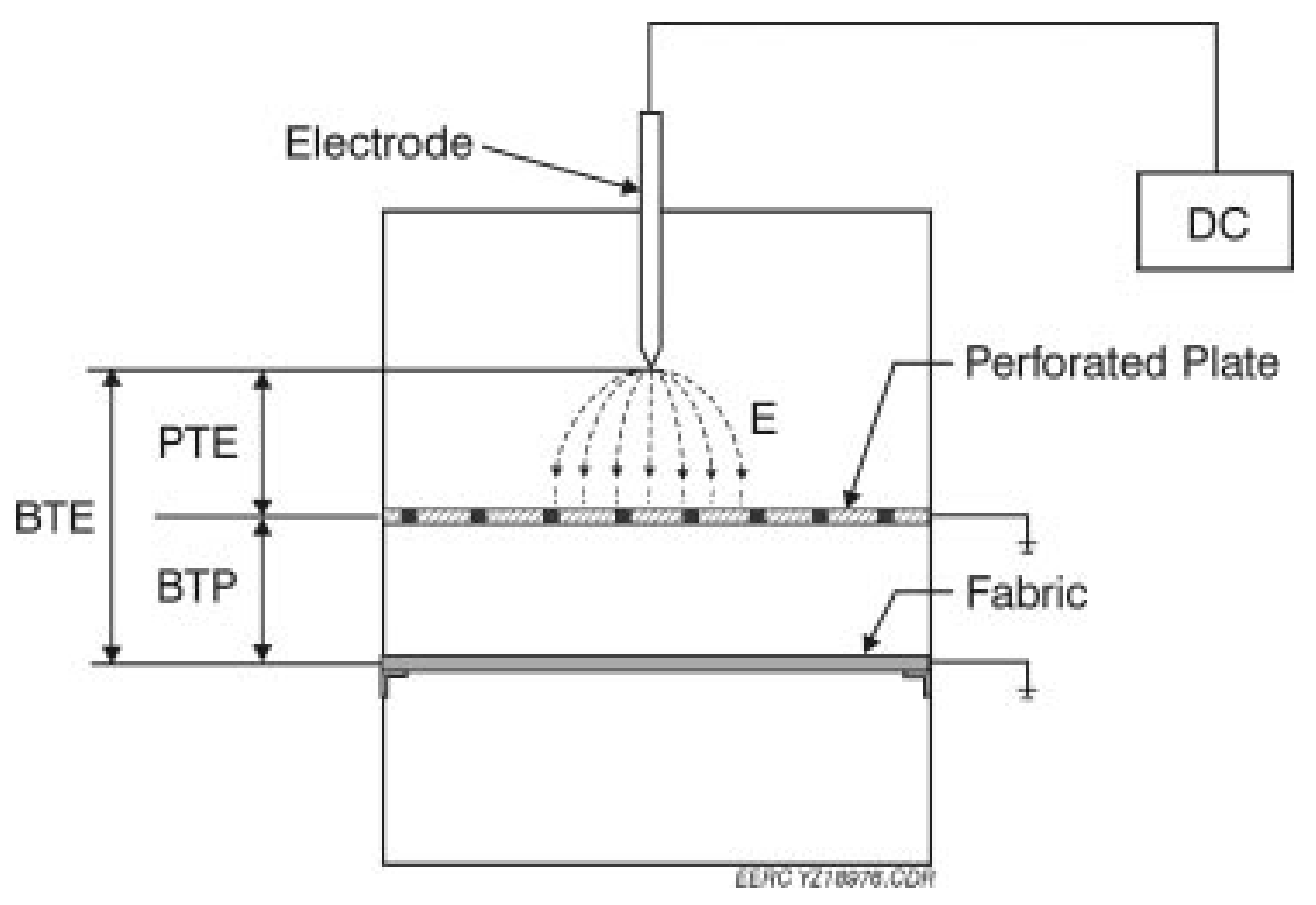

Figure 1. Schematic of the bench-scale AHPC.

The current to the fabric was first measured as a function of BTE without the perforated plate for two different bag fabrics: CBCM (conductive bag with conductive membrane) and CBNM (conductive bag with nonconductive membrane). The VI curves are shown in Figures 2 and 3 as a function of BTE. At a normal operating condition, an applied voltage of $65 \mathrm{kV}$ and a BTE spacing of 6 in. $(152.4 \mathrm{~mm})$, the current to the bag was $65 \mu \mathrm{A}$ for CBCM and $131.4 \mu \mathrm{A}$ for CBNM, respectively, accounting for more than $50 \%$ of the total generated current, respectively. The high current to the bag is regarded as the reason for the observed bag damage. The experimental results showed the current to bag increased with the decreasing distance between the electrode and the bag for both the fabrics.

The perforated hole size is very important to the AHPC performance. It will determine the extent of the reduced bag current as well as the dust loading toward the bags. The effect of the hole size of the perforated plate on bag current was investigated by measuring the current to bag at $\mathrm{BTE}=4.0$ in. $(101.6 \mathrm{~mm})$ and $\mathrm{BTP}=1.0 \mathrm{in} .(25.4 \mathrm{~mm})$ for three different hole sizes: $0.75,1.0$ and $1.5 \mathrm{in} .(19.1,25.4,38.1 \mathrm{~mm})$. The bag current was $3.4 \mu \mathrm{A}$ for the perforated hole size of $0.75 \mathrm{in} .(19.1 \mathrm{~mm})$ and increased to $11.9 \mu \mathrm{A}$ for the hole size of $1.5 \mathrm{in}$. ( $38.1 \mathrm{~mm}$ ) when they were both at the same voltage of $65 \mathrm{kV}$ (shown in Figure 4), which indicated the perforated plate with smaller hole size protected the bag better than that of a larger hole size in terms of reducing bag current. It is noted that even the perforated plate with a hole size of $1.5 \mathrm{in}$. $(38.1 \mathrm{~mm}) \mathrm{can}$ remove more than $95 \%$ of the initial current flow to the bag. A cold-flow test was then carried out in the AHPC pilot unit under the perforated plate configuration to confirm the bench-scale results. Both the perforated plate hole size and the bag-to-perforated plate spacing were varied to examine their corresponding effects on the bag current. The experimental data are plotted in 


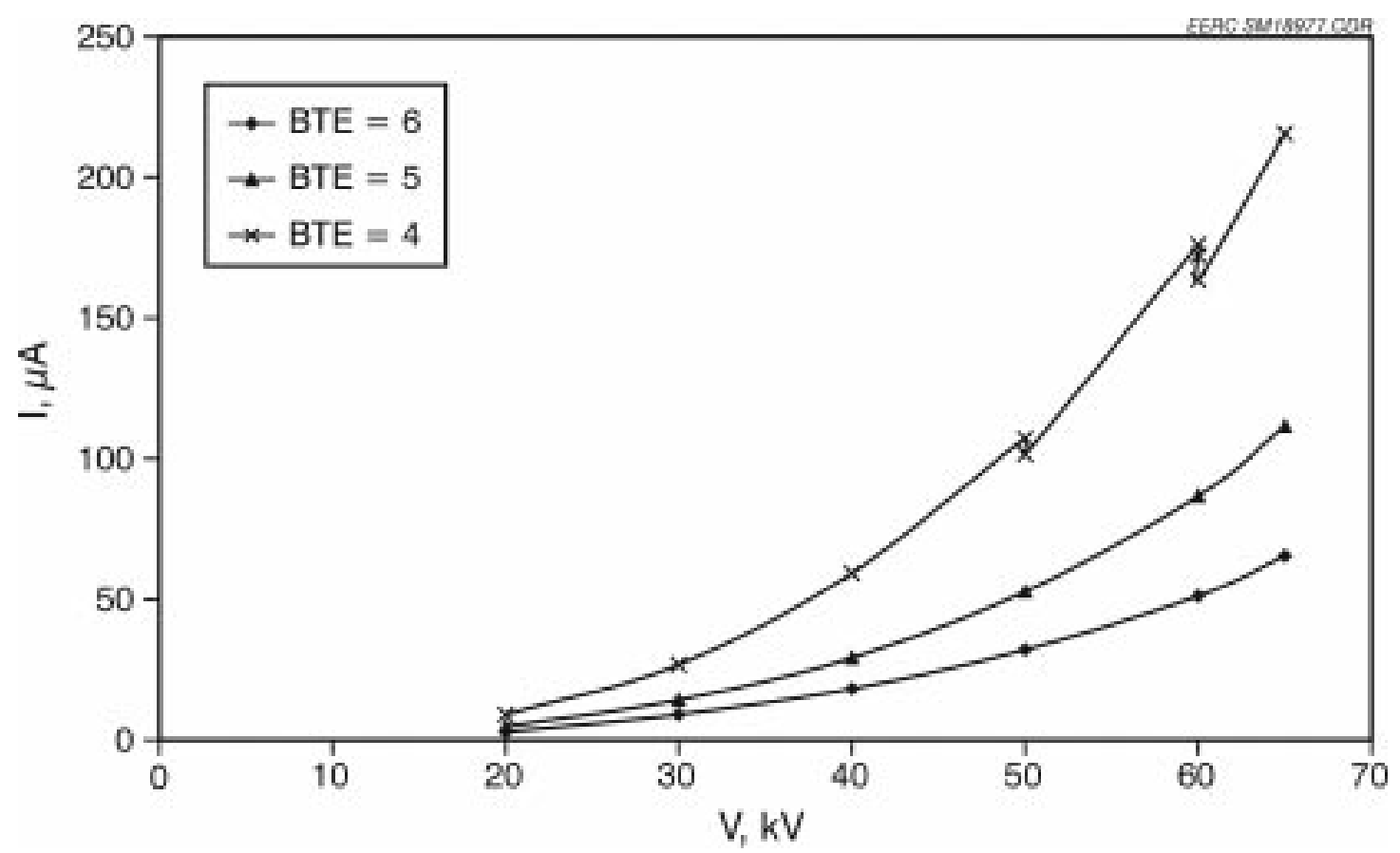

Figure 2. Current to the bags as a function of spacing between electrode and the bag (no perforated plate, $\mathrm{CBCM}$ ).

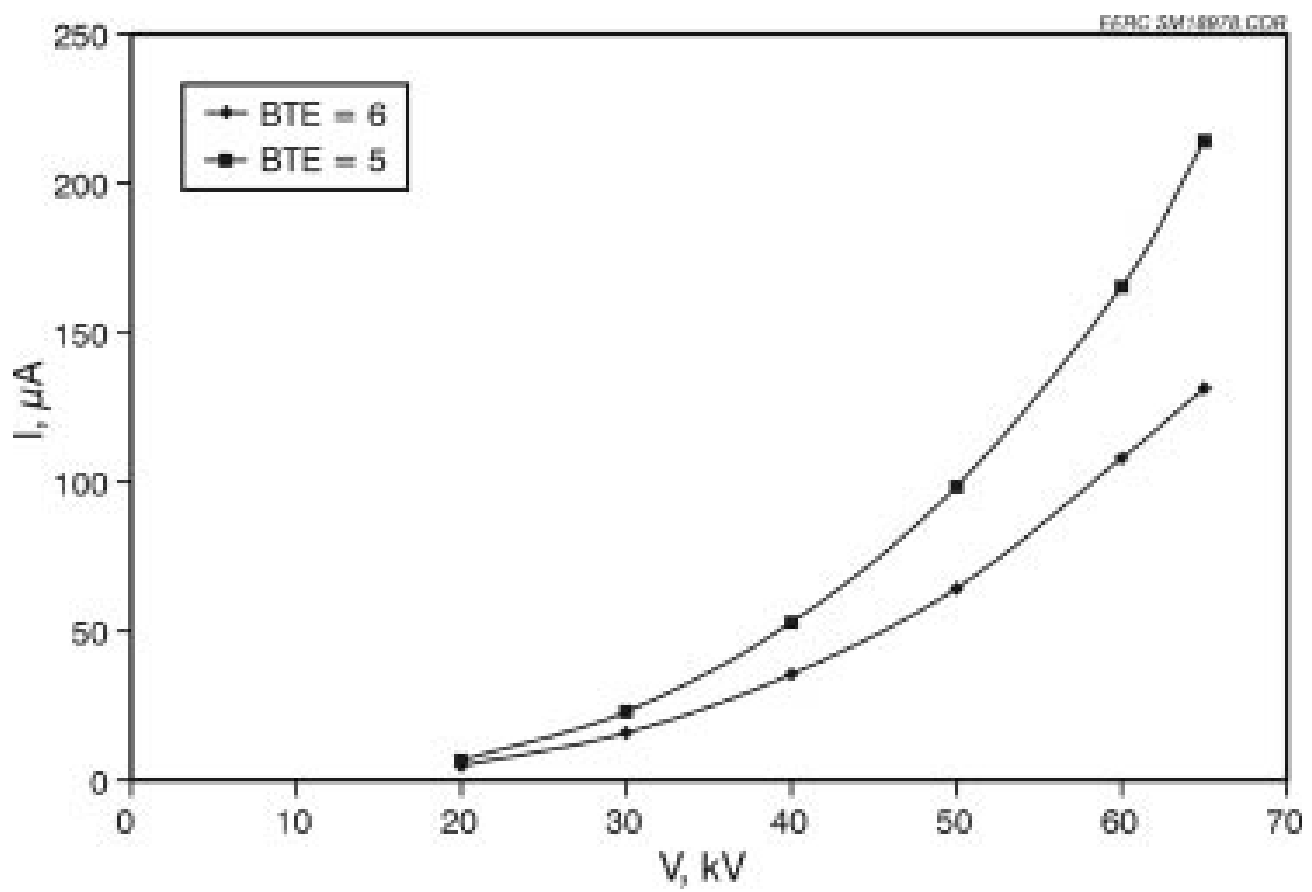

Figure 3. Current to the bags as a function of spacing between the electrode and the bag (no perforated plate, CBNM). 


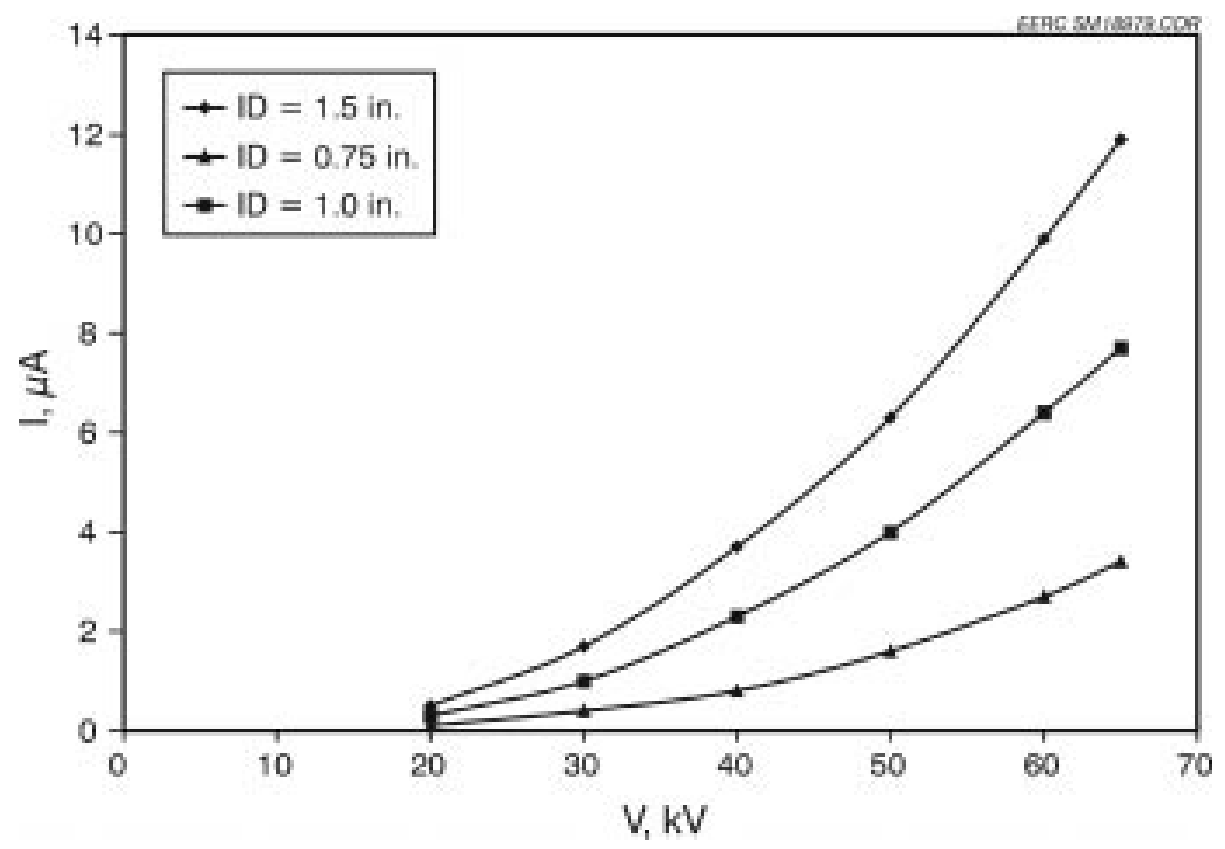

Figure 4. Current to the bag in the presence of different perforated plates (bench-scale, CBCM, BTP:PTE = 1:3).

Figures 5 and 6 . The bag current was less than $1 \mu \mathrm{A}$ for the perforated plate with 0.75 -in. (19.1-mm) hole size. The bag current was in the range of 2.4-3.3 $\mu \mathrm{A}$ at an applied voltage of $50 \mathrm{kV}$ for the perforated plate with 2-in. (50.8- $\mathrm{mm}$ ) hole size, which was significantly reduced compared to the bag current without the perforated plate. It shows the smaller-hole-sized perforated plate results in a lower current to the bag which is the same as the results obtained in the bench-scale experiments. The bag current was also examined as a function of BTP. The bag current was $2.4 \mu \mathrm{A}$ at a BTP of 3 in. (76.2 mm) (Figure 6) and an applied voltage of $50 \mathrm{kV}$ for the 2-in. (50.8-mm)-hole-sized perforated plate and increased to $3.3 \mu \mathrm{A}$ when the BTP was adjusted to 2 in. $(50.8 \mathrm{~mm}$ ) (Figure 5), indicating some dependence of bag current on the distance from the bag to the perforated plate.

The above experimental results demonstrated sufficient protection to the bag by using perforated plates (even at a large hole size). The CBCM fabric will be used in the later experiments because it dissipates the electric charge on bag surface more efficiently.

\subsection{TWO DIMENSIONAL (2-D) MODEL OF ELECTRICAL FIELD FOR THE PILOT-SCALE AHPC IN THE PRESENCE OF PERFORATED PLATE}

To evaluate the effect of the perforated plate on the electric field strength, a theoretical 2-D dimensional modeling was developed to simulate the electric field in the AHPC pilot-scale configuration in the presence of perforated plates of different hole sizes. The governing electrostatic equation for the region outside of the corona sheath is Poisson's equation: 


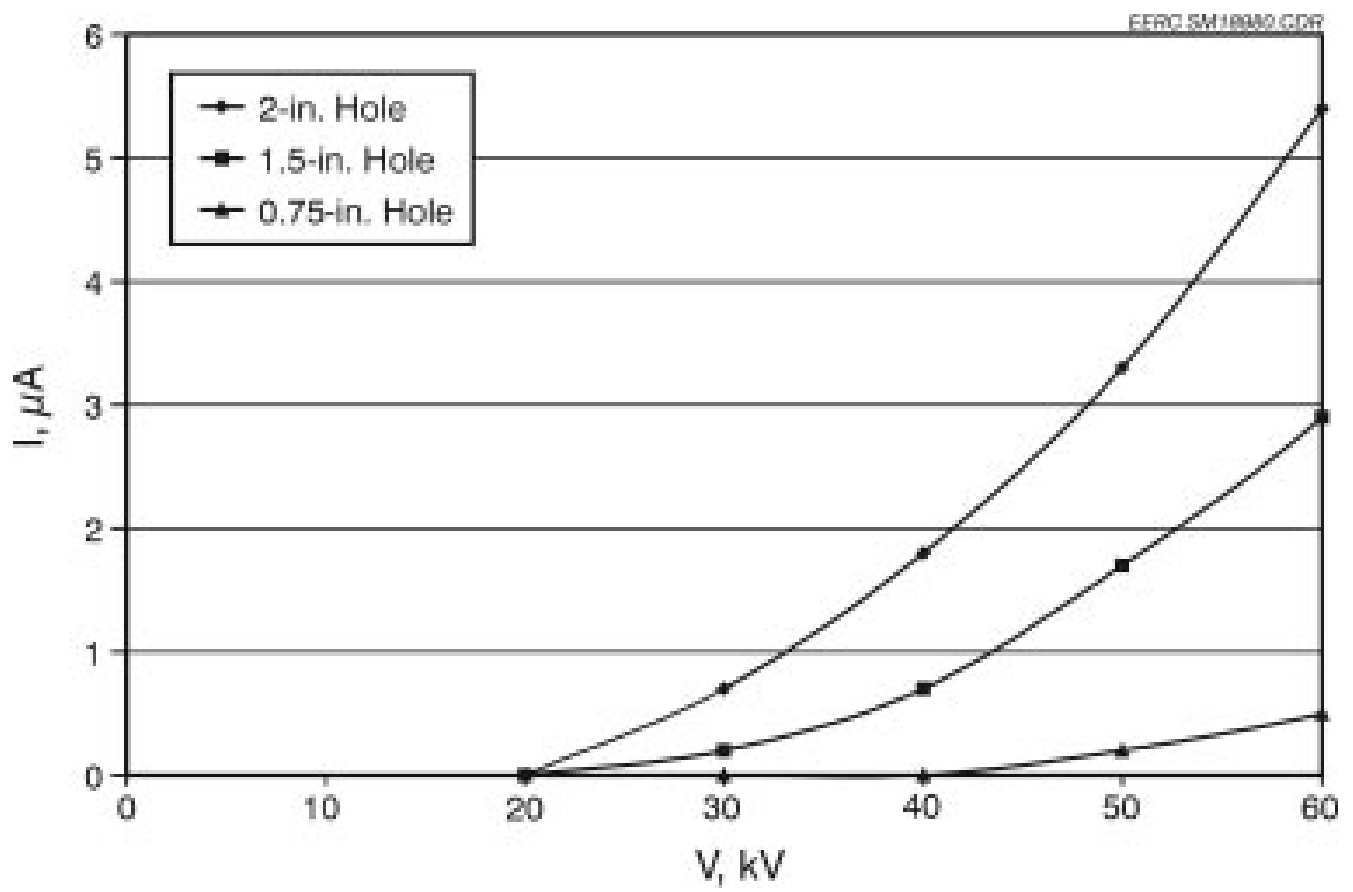

Figure 5. Current to the bag in the presence of different perforated plates (pilot unit, $\mathrm{CBCM}$, $\mathrm{BTP}=2$ in.).

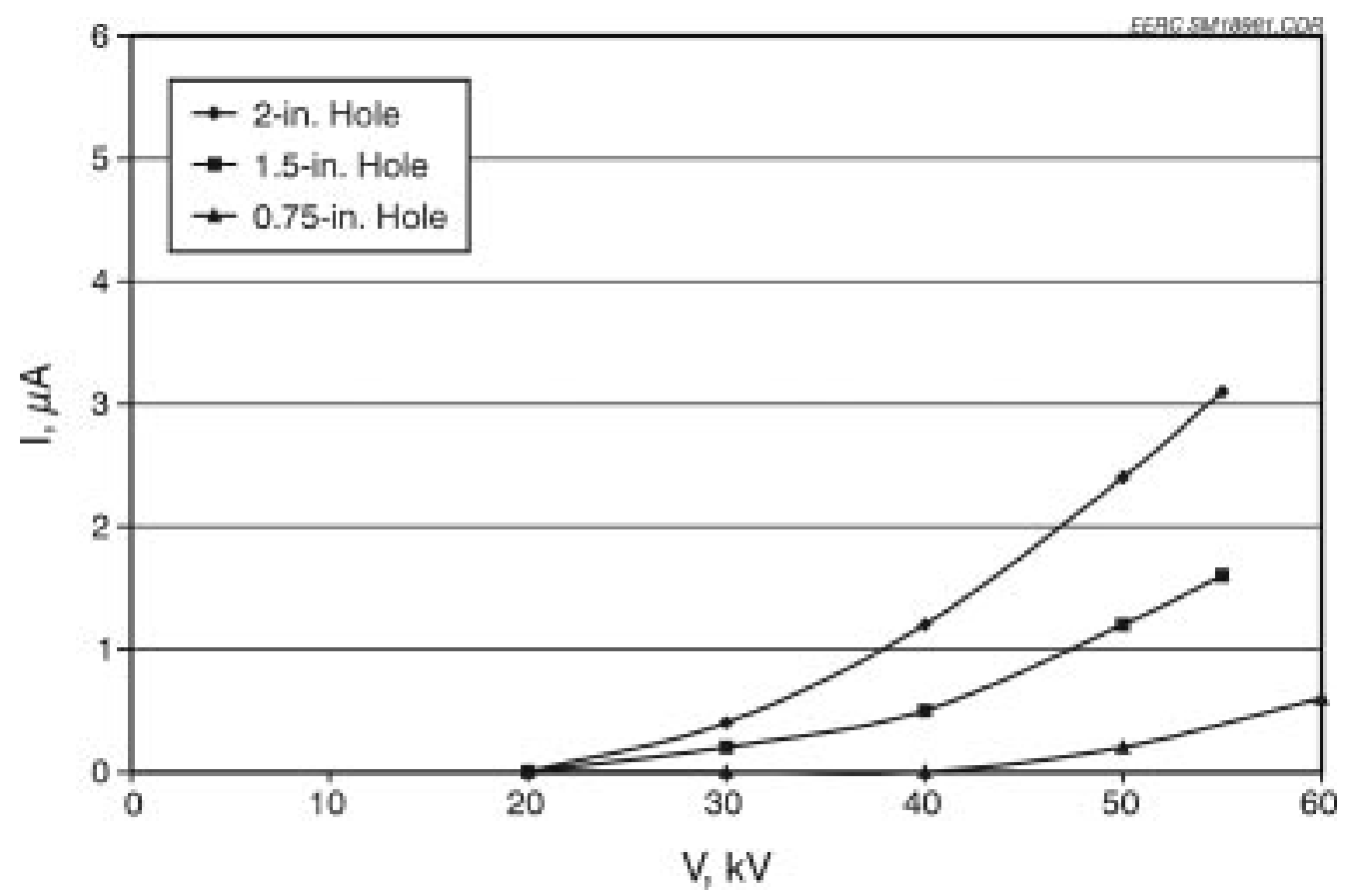

Figure 6. Current to the bag in the presence of different perforated plates (pilot unit, $\mathrm{CBCM}, \mathrm{BTP}=3$ in.). 


$$
\nabla^{2} \varphi=-\frac{\rho}{\varepsilon}
$$

By assuming a steady-state, the conservation of the current equation is:

$$
\nabla \cdot(\rho \beta E)=0
$$

where $\varphi$ is electrical potential, $\beta$ is ionic space charge density, $\varepsilon$ is a constant, gas permittivity, $\mathrm{E}$ is electrical field, and $\beta$ is negative ion mobility. The above equations were solved with the finite element method to compute the electrical field distribution in the system. The calculated equipotential lines are shown in Figures 7-10. The electrical potential was set to $60 \mathrm{kV}$ on the electrode. The simulation showed the electrical potential was maintained as high as 2000 volt around the bag surface without the perforated plates and dramatically decreased to 200 volt because of the grounded perforated plates. The model predicted the bags were well protected even at a larger hole size of 2.5 in. $(63.5 \mathrm{~mm})$.

\section{$5.0 \quad 9000-\operatorname{acfm}\left(255-\mathrm{m}^{3} / \mathrm{min}\right)$ AHPC DESIGN CHANGES AND TEST RESULTS}

Based on the $200-$ acfm $\left(5.7-\mathrm{m}^{3} / \mathrm{min}\right)$ results, a perforated plate configuration was designed and installed on the $9000-\mathrm{acfm}\left(255-\mathrm{m}^{3} / \mathrm{min}\right)$ slipstream pilot unit at the Big Stone power plant. The differences between the new perforated plate design and the previous AHPC can be seen by comparing Figure 11 with Figure 12. Figure 11 is simplified top view of the 9000 -acfm $\left(255-\mathrm{m}^{3} / \mathrm{min}\right)$ AHPC configuration at the start of Phase III, which had a plate-to-plate spacing of 23.6 in. (599.4 mm). This arrangement was already more compact than the original Phase II AHPC configuration, which had a plate-to-plate spacing of 29 in. $(736.6 \mathrm{~mm})$. Since the overall size of the housing was not changed, this resulted in unused space, shown in Figure 11. In both cases, the bag row spacing is the same as the plate-to-plate spacing. For the perforated plate configuration (Figure 12), the bag spacing was not changed to allow using the same tube sheet as in the previous configuration (Figure 11). However, the distance from the discharge electrodes to the plates is now 5.5 in. $(139.7 \mathrm{~mm})$, compared to $3.9 \mathrm{in} .(99.1 \mathrm{~mm})$ previously. With this configuration, the distance from the bags to the perforated plates was selected to be 3 in. $(76.2 \mathrm{~mm})$ in order to be on the conservative side. If this distance were reduced to $2 \mathrm{in}$. (50.8 $\mathrm{mm})$ and the electrode-to-plate distance were reduced to $4 \mathrm{in.}(101.6 \mathrm{~mm})$, the bag rows could potentially be moved $5 \mathrm{in}$. $(127 \mathrm{~mm})$ closer, which would correspond to a $21 \%$ reduction in footprint area, compared to the arrangement shown in Figure 12. Therefore, one of the obvious advantages of the new perforated plate configuration is the potential to make the AHPC significantly more compact than the earlier design.

Another difference is that directional electrodes are not required with the perforated plate design. With the previous design, directional electrodes (toward the plate) were needed to prevent possible sparking to the bags. This means that conventional electrodes can now be used with the AHPC. Electrode alignment is also now less critical because an out-of-alignment electrode now would simply result in potential sparking to the nearest grounded perforated plate, whereas with the old design, an out-of-alignment electrode could result in sparking to a bag and possible bag damage. 


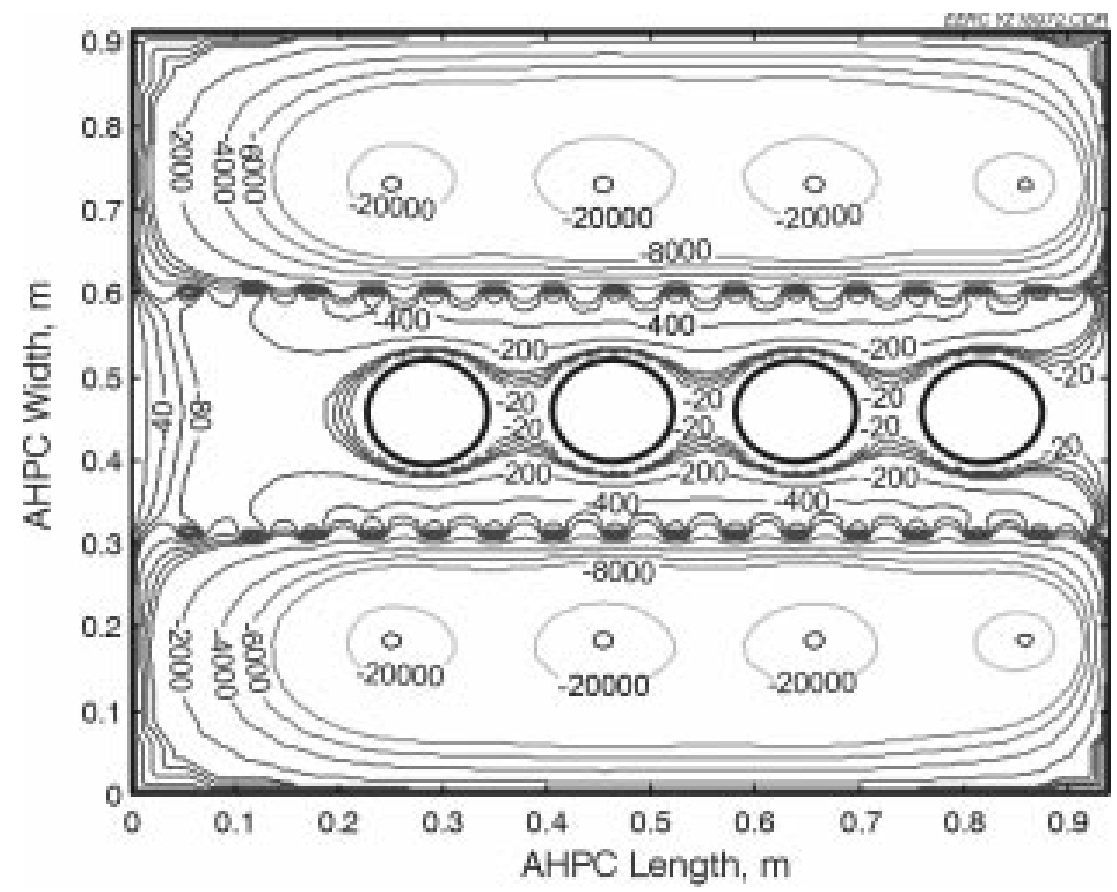

Figure 7. Electrical potential distributed in the pilot unit AHPC with the 1.0-in. hole size perforated plates.

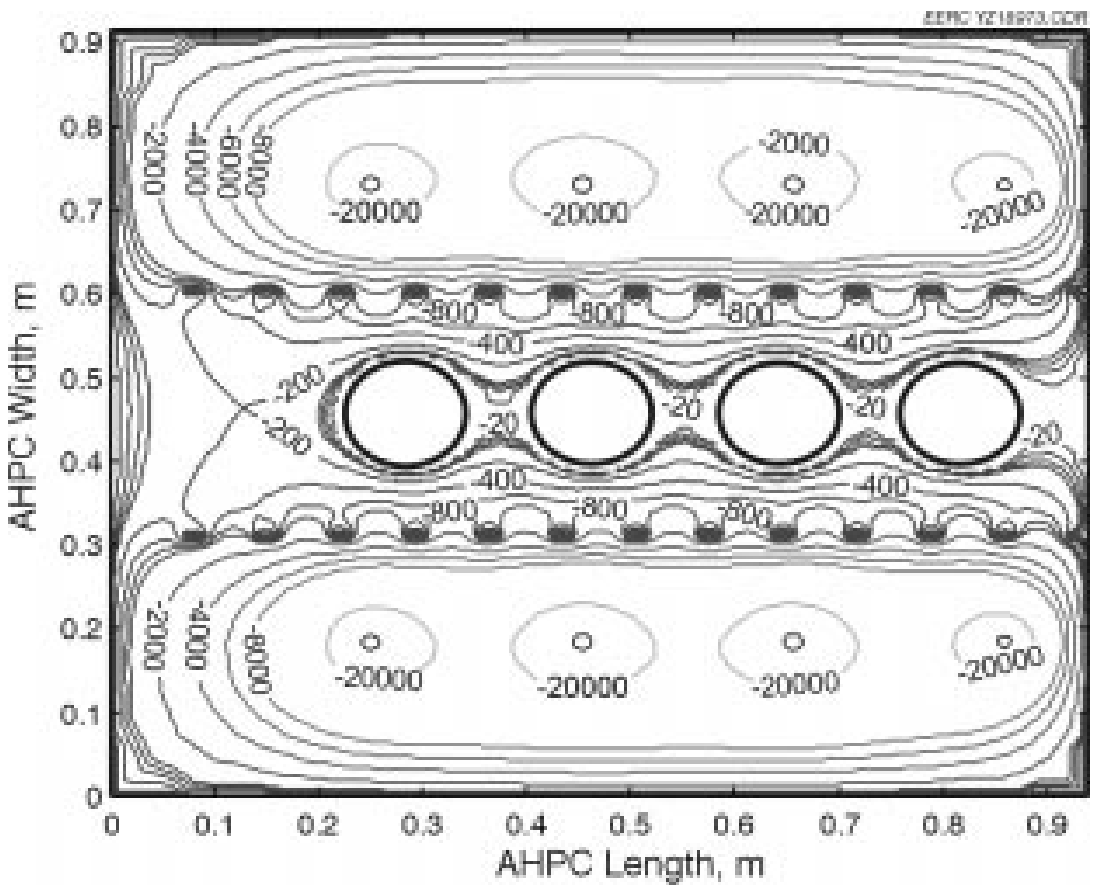

Figure 8. Electrical potential distributed in the pilot unit AHPC with the 2.0-in. hole size perforated plates. 


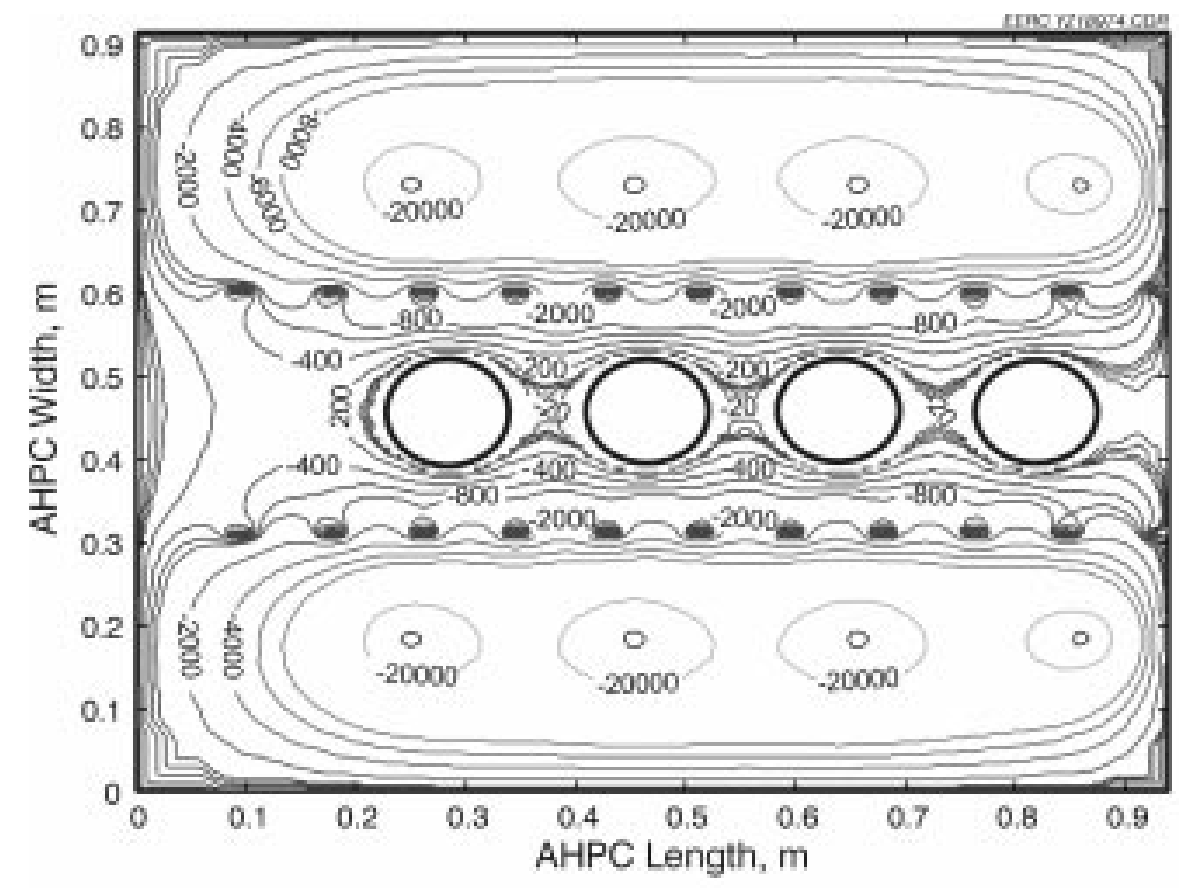

Figure 9. Electrical potential distributed in the pilot unit AHPC with the 2.5-in. hole size perforated plates.

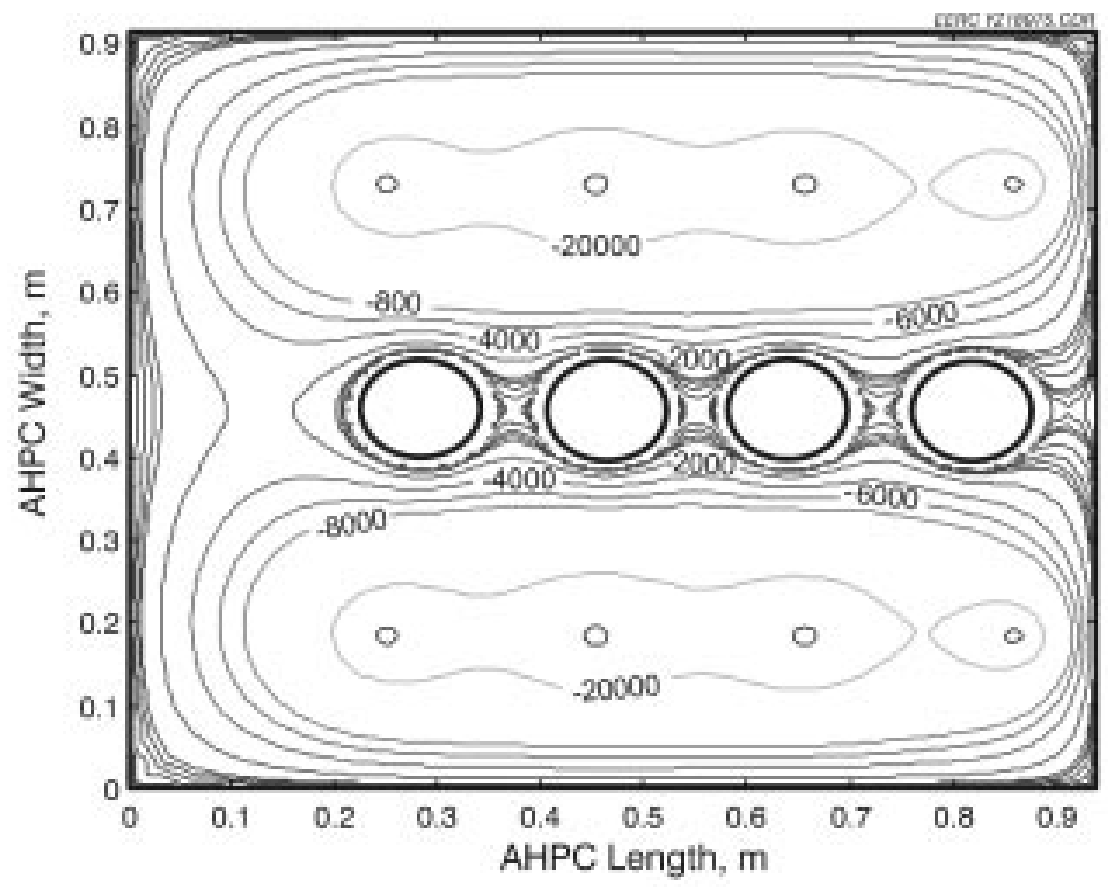

Figure 10. Electric potential distribution in the AHPC pilot unit without the perforated plates. 


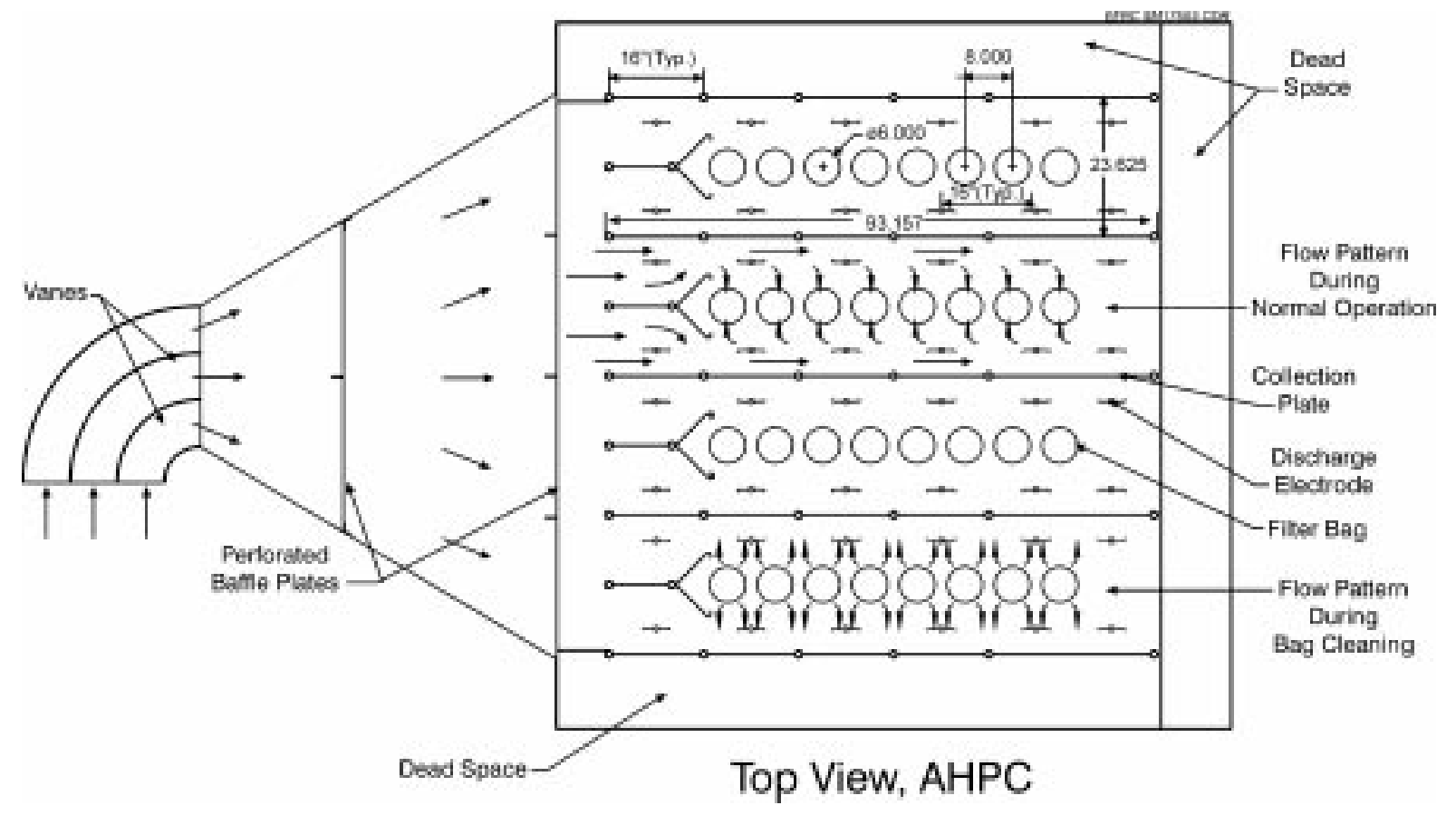

Figure 11. Top view of the $9000-\operatorname{acfm}\left(255-\mathrm{m}^{3} / \mathrm{min}\right)$ AHPC, as modified at the start of Phase III.

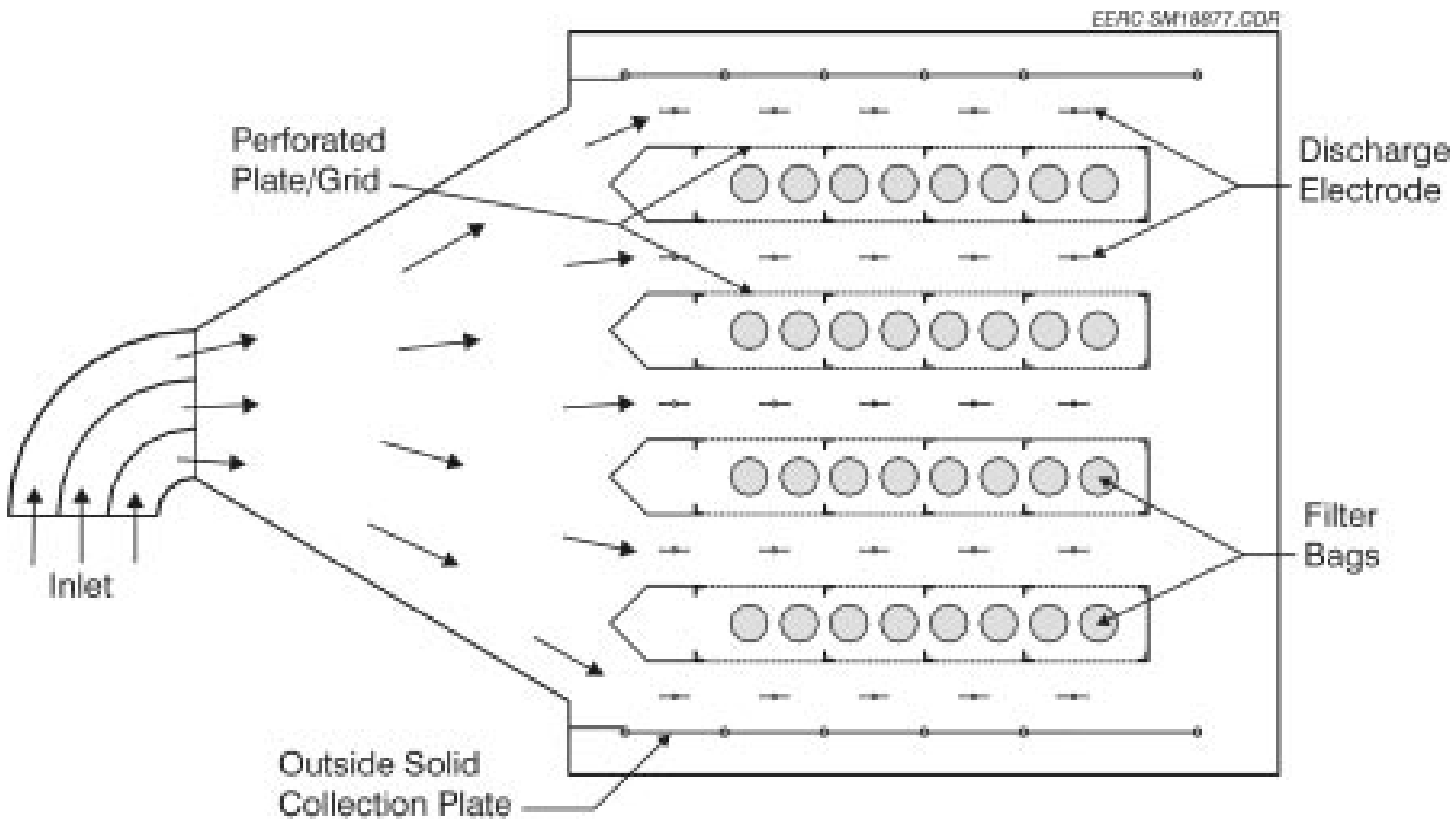

Figure 12. Top view of the perforated plate configuration for the $9000-\mathrm{acfm}\left(255-\mathrm{m}^{3} / \mathrm{min}\right)$ AHPC. 
While the overall AHPC concept is unchanged in that precollection of $>90 \%$ of the dust and enhanced bag cleaning are key features, the purpose of the plates is somewhat different. Now the plates serve two very important functions: as the primary collection surface and as a protective grid for the bags. With approximately $45 \%$ open area, the hope was that there would be adequate collection area on the plates to collect the precipitated dust while not restricting the flow of flue gas toward the bags during normal filtration. During pulse cleaning of the bags, the hope was that most of the reentrained dust from the bags would be forced back through the perforated plates into the ESP zone. From results to date, it appears that this configuration provides better ESP collection than the previous design and does not impair bag cleanability. The better ESP collection efficiency is likely the result of forcing all of the flue gas through the perforated plate holes before reaching the bags. This ensures that all of the charged dust particles pass within a maximum of one-half of the hole diameter distance of a grounded surface. In the presence of the electric field, the particles then have a greater chance of being collected. In the old AHPC design, once the gas reached the area between the electrodes and bags, it would be driven toward the bags rather than the plates, and a larger fraction of the dust was likely to bypass the ESP zone.

The modifications to the field AHPC were completed in February to mid-March 2001. Photos of the new plates during installation are shown in Figures 13 and 14. The AHPC was started March 15 and has operated continuously to date except for an unplanned plant outage March 25-26. Operating results from March 15 through April 9 are shown in Figures 15-17. Performance to date is much better than any of the previous tests with the 9000 -acfm $\left(255-\mathrm{m}^{3} / \mathrm{min}\right)$ AHPC.

A previously established performance goal for the AHPC was a pulse-cleaning interval of at least $10 \mathrm{~min}$ at an $\mathrm{A} / \mathrm{C}$ ratio of $12 \mathrm{ft} / \mathrm{min}(3.7 \mathrm{~m} / \mathrm{min})$ and an 8 -in. W.C. (2.0-kPa) pressure drop. The bag-cleaning interval for the recent tests has ranged from 26-68 min at a pressure drop less than 8 in. W.C. $(2.0 \mathrm{kPa})$. Another significant improvement is the very low $\mathrm{K}_{2} \mathrm{C}_{\mathrm{i}}$ values, as shown in Figure 16. These values have consistently been in the range from 1.8 to 3 compared to 5 in the best case for previous results to over 15 during times of marginal performance.

Furthermore, the residual or minimum drag appears to have leveled off in the range from 0.50 to 0.55 (see Figure 17). During the first 2 weeks of operation from March 15-30, 2001, a number of the test parameters were adjusted to fine-tune the performance, which is one of the reasons for the varying bag-cleaning intervals. However, from April 4-9, the unit has been operated in a very steady mode at an $\mathrm{A} / \mathrm{C}$ ratio of $12 \mathrm{ft} / \mathrm{min}(3.7 \mathrm{~m} / \mathrm{min})$, a bag-cleaning interval in the range from 45 to 60 min, $\mathrm{K}_{2} \mathrm{C}_{\mathrm{i}}$ values in the range from 1.8 to 2.0, a minimum drag of 0.50 to 0.52 , and an average pressure drop of 7.2 in. W.C. $(1.79 \mathrm{kPa})$. This impressive improvement in all of these parameters was achieved at a 75 psi pulse-cleaning pressure and clearly demonstrates significantly better performance with the new perforated plate configuration, compared to the Phase II or previous Phase III results.

The first bag inspection with the perforated plate configuration will be completed during the next planned plant outage from May 8-14. However, from the 200 -acfm results $\left(5.7-\mathrm{m}^{3} / \mathrm{min}\right)$ and no observed back corona or sparking to the bags, no electrical damage is expected. 


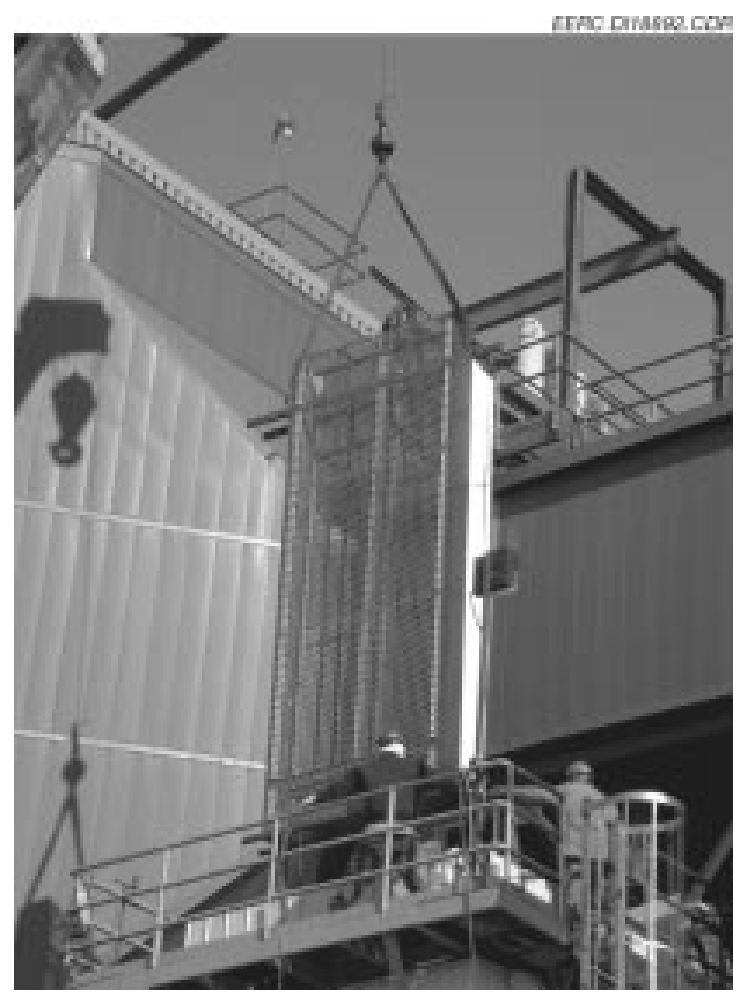

Figure 13. Installing the perforated plates in the $9000-\operatorname{acfm}\left(255-\mathrm{m}^{3} / \mathrm{min}\right)$ AHPC at the Big Stone power plant, March 2001.

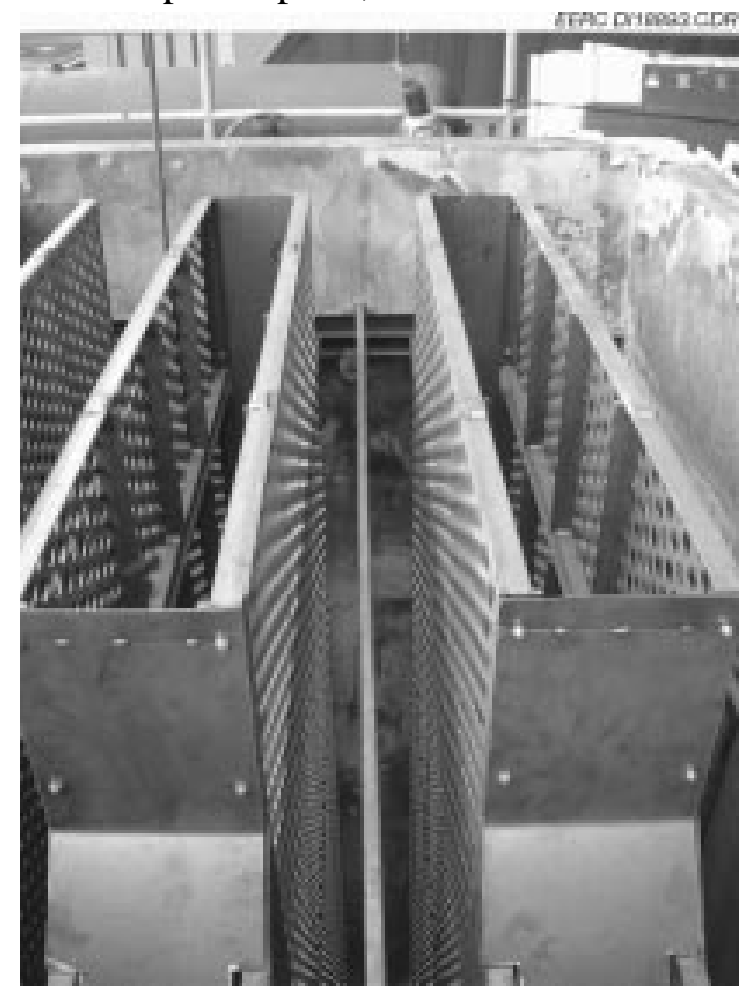

Figure 14. Perforated plates as installed in the $9000-\mathrm{acfm}\left(255-\mathrm{m}^{3} / \mathrm{min}\right)$ AHPC before replacing the tube sheet. Bags fit inside each pair of perforated plates. 


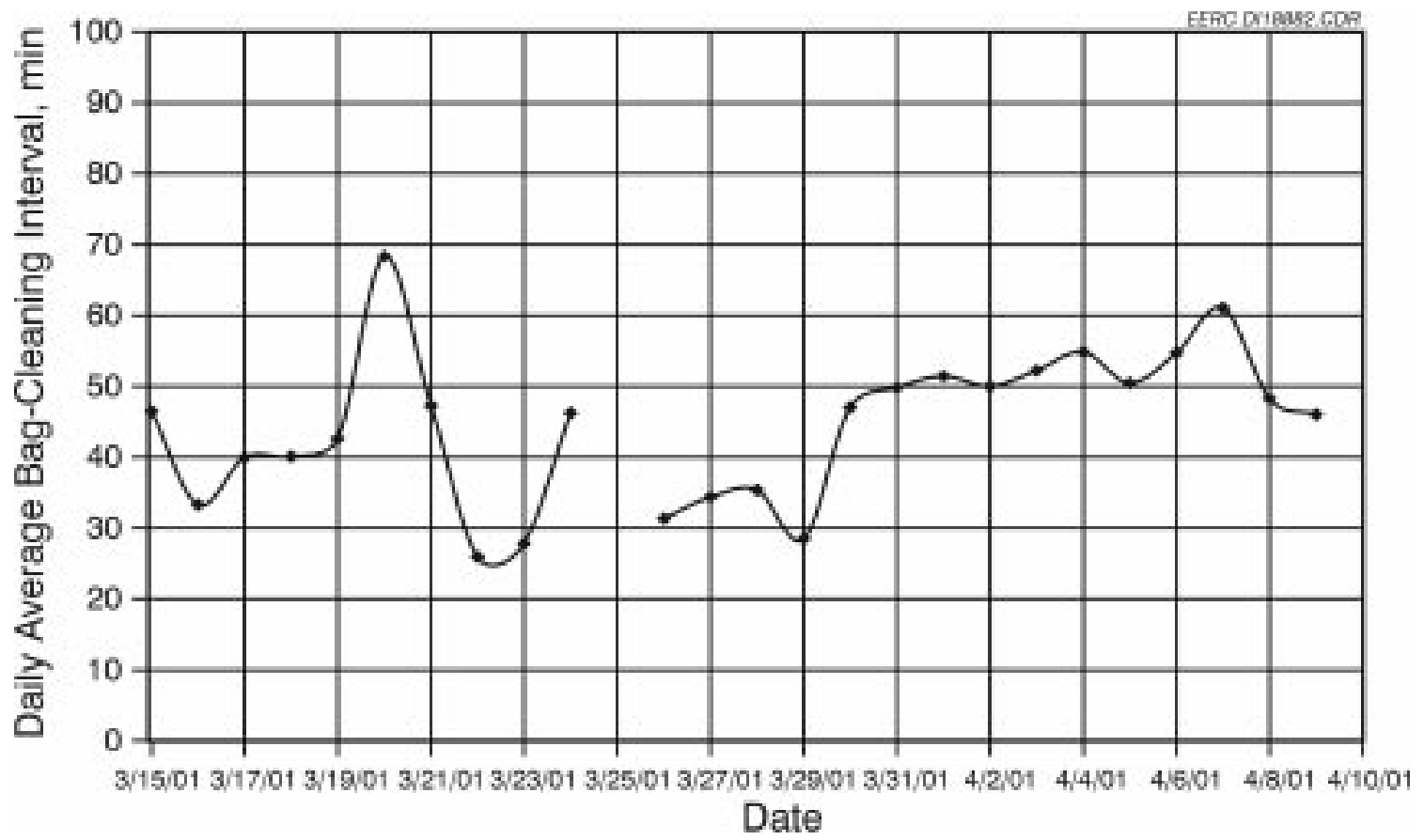

Figure 15. Daily average bag-cleaning interval.

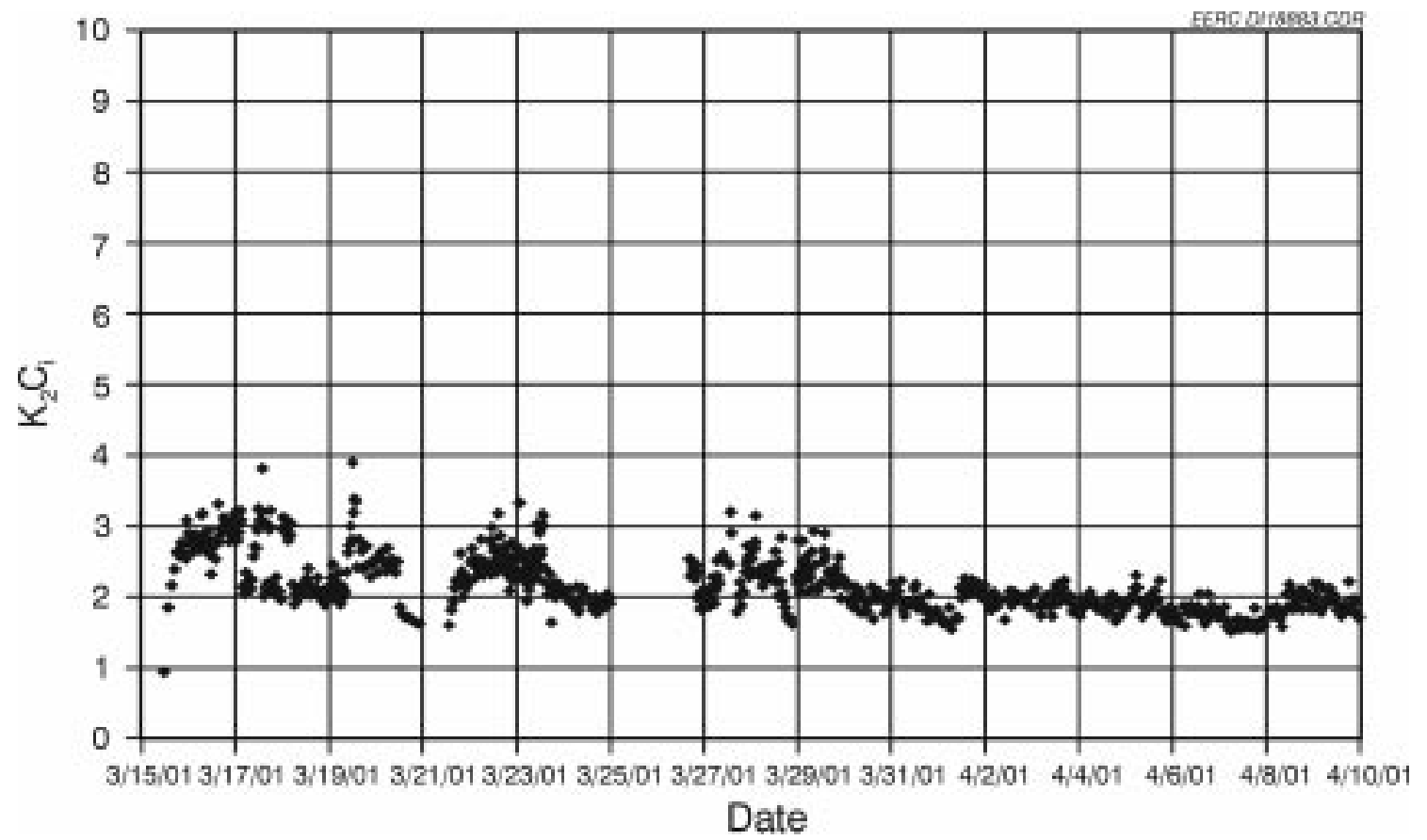

Figure $16 . \mathrm{K}_{2} \mathrm{C}_{\mathrm{i}}$. 


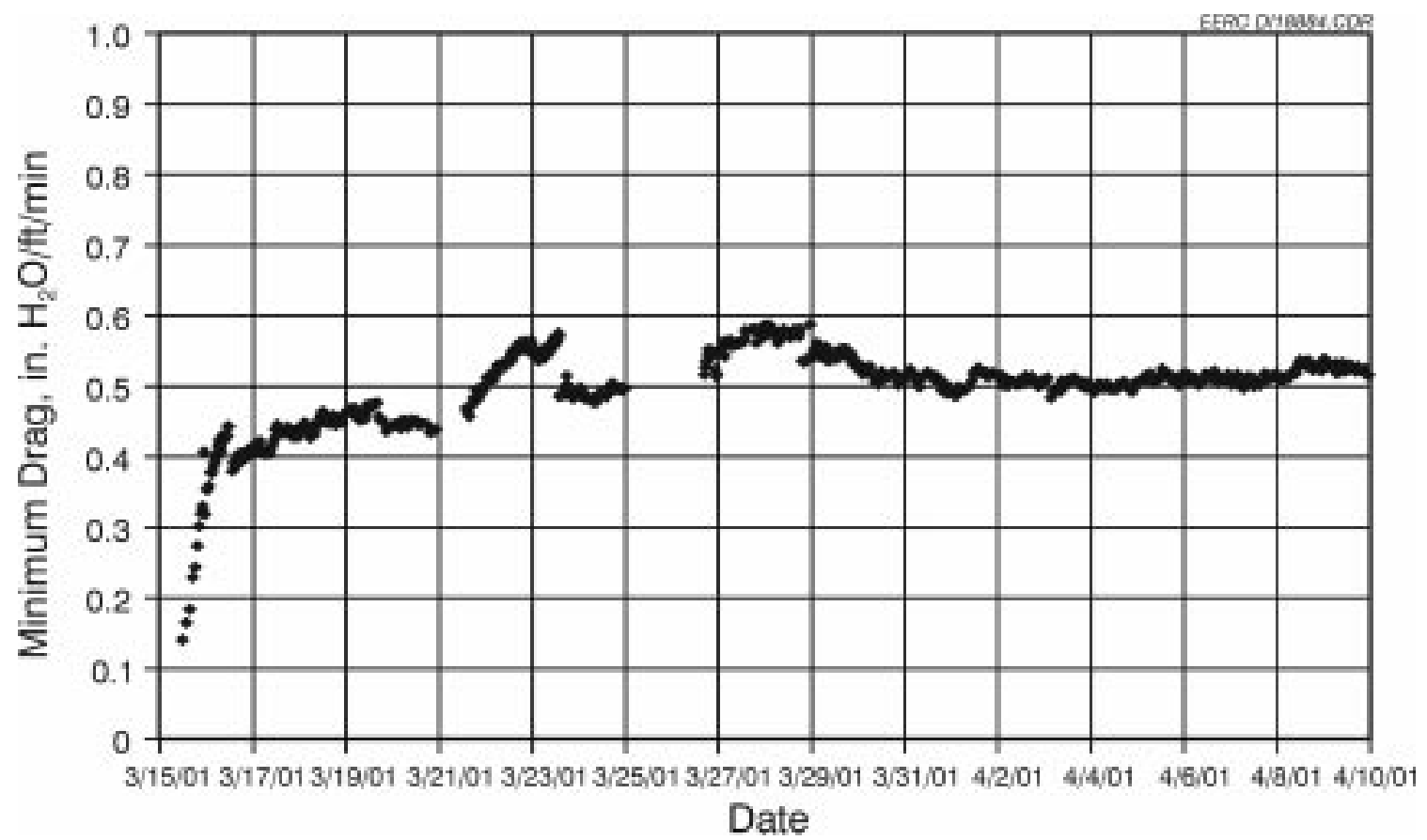

Figure 17. Minimum drag.

In summary, the new perforated plate configuration appears to have completely solved the bag damage problem and to have achieved significantly better performance than the previous AHPC configuration.

\subsection{PLANS FOR NEXT QUARTER}

Plans are to continue operating the $9000-\mathrm{acfm}\left(255-\mathrm{m}^{3} / \mathrm{min}\right)$ AHPC through June 2001 under Phase III. Several operating parameters such as A/C ratio, pulse trigger pressure, pulsecleaning pressure, and temperature will be evaluated to examine their effects on AHPC performance with the perforated plate configuration. 